\title{
Decomposing changes in first birth trends: quantum, timing, or variance
}

\author{
Ryohei Mogi ${ }^{1, *}$ and Michael Dominic del Mundo ${ }^{2}$
}

\begin{abstract}
In high-income countries, women and men born since the 1940s have delayed the birth of their first child, more of them have remained childless, and the timing of the first birth has become more diverse in these cohorts. The interaction between these three trends makes the research on first birth patterns more complex. This study has two main aims: (1) we introduce an alternative index, Expected Years Without Children (EYWC), to quantify changes in first birth behaviour; and (2) we decompose the changes in EYWC over time into three effects: remaining permanently childless, postponing the first birth, and the expansion of the standard deviation of the mean age at first birth. Using data from the Human Fertility Database, EYWC is calculated to illustrate time trends among women born in the 1910s-1960s in eight countries with longer series of data on cohort first birth trends: Canada, the Czech Republic, Japan, the Netherlands, Norway, Portugal, Sweden, and the United States. Our decomposition shows that the changes in EYWC are mainly attributable to postponement in North America and northern Europe, whereas these changes are largely due to increasing shares of women remaining childless in Japan and Portugal.
\end{abstract}

Keywords: childlessness; postponement of first birth; decomposition method; Coale-McNeil model; life table

\section{Introduction}

The share of childless women has steadily increased in recent decades in highincome countries. For example, according to Kreyenfeld and Konietzka (2017), more than $20 \%$ of women in German-speaking countries were childless at the end

\footnotetext{
${ }^{1}$ Center for Demographic Studies, Barcelona, Spain

${ }^{2}$ Population Institute, Palma Hall, University of the Philippines, Quezon City, Philippines

${ }^{*}$ Correspondence to: Ryohei Mogi, rmogi@ced.uab.es
} 
of their reproductive period since the 1950s birth cohorts. This increasing trend can be observed throughout Europe (Beaujouan et al. 2016; Miettinen et al. 2015; Kreyenfeld and Konietzka 2017), North America (the US: Frejka 2017, Canada: Ravanera and Beaujot 2014) and Japan (Raymo et al. 2015). It has also been projected that the future level of childlessness will increase as the fertility patterns of countries diverge (Sobotka 2017). Becoming a parent or remaining childless influences various aspects of a man's or a woman's life, including the individual's income (Budig et al. 2012), health (Kendig et al. 2007), old-age well-being (Huijts et al. 2013; Zhang and Hayward 2001), and support networks (Albertini and Kohli 2009). Therefore, it is important that we gain a deeper understanding of the trend of childlessness. The increase in the number of childless women has coincided with an increase in the mean age at first birth. For instance, in the OECD countries, the mean age at first birth has increased by about one year each decade since the 1970s (Mills et al. 2011). Thus, in these decades, levels of childlessness have risen (quantum changes) and the first birth has been increasingly postponed (timing changes).

The most common indices used to measure first birth trends, the proportion of childless women at age 50 and the mean age at first birth, are useful for studying either quantum changes or timing changes, but not for studying both. This is simply because the proportion of childless women does not take into account the timing changes (e.g., the same proportion of childless women can reflect different mean ages at first birth), and the mean age at first birth per se does not show quantum changes. Previous research has investigated how changes in the timing of the first birth affect the level of childlessness. For instance, Kneale and Joshi (2008) explored the extent of childbirth postponement and projected its impact on eventual levels of childlessness in the UK. Similarly, te Velde et al. (2012) estimated the effect of postponement of entry into motherhood on permanent involuntary childlessness in six European countries.

In this study, by contrast, we suggest an alternative index that takes both quantum and timing changes into account in a single index: Expected Years Without Children (EYWC). This index measures the average length of life women spend without children during their reproductive period by estimating both the life years of women who remained childless at the end of their reproductive period (quantum) and the life years of women before they had a child (timing). The concept of EYWC was previously introduced by Bongaarts and Feeney (2006) in fertility research, and was employed by Andersson et al. (2017) to describe contemporary family changes using a life table method. However, these authors did not focus on the index per se, nor did they depict its trends. Therefore, the first aim of this study is to present the trend in EYWC in order to show how first birth trends have changed due to both quantum and timing changes.

Our second aim is to quantify which of two effects, remaining permanently childless or postponing the first birth, has the most impact on changes in first birth behaviour. Although those two phenomena are the main focus in this study, an additional component, the variance in the age at first birth, is investigated. When the mean age at first birth increases, the variance in the timing of the first birth in a 
given population becomes larger (Kohler and Philipov 2001). In part because of this expansion of the timing of the first birth, the family life courses of women diverge more across birth cohorts (Elzinga and Liefbroer 2007). Therefore, we quantify the effects of remaining permanently childless, postponing the first birth, and the expansion of the timing of the first birth on the changes in EYWC over time using a decomposition method presented by Mogi and Canudas-Romo (2018).

In the following section, we explain our methods - a parametric model for a first birth, the main measure used to describe the first birth trend (EYWC), and the decomposition method - as well as the data we used. In the third section, we present the trend in EYWC and the results of its decomposition. In the final section, we conclude by discussing our findings, the limitations of our study, and future research directions.

\section{Data and methods}

\subsection{Data}

In this study, we used female population counts by age and birth cohort and birth counts by birth order and mother's cohort from the Human Fertility Database (HFD) (Human Fertility Database 2018). To avoid problems arising from truncation and censoring bias, we used completed cohort fertility data only. Based on these criteria, data from eight countries were selected: Canada (1929-1962 birth cohort), the Czech Republic (1935-1965 birth cohort), Japan (1953-1965 birth cohort), the Netherlands (1935-1963 birth cohort), Norway (1952-1965 birth cohort), Portugal (1944-1966 birth cohort), Sweden (1955-1965 birth cohort), and the US (19181965 birth cohort).

\subsection{Coale-McNeil model for first birth}

While the parametric model for overall fertility is well developed (see, for example, Kostaki and Paraskevi 2007), there are few models that measure the first birth. In this study, we use the Coale-McNeil model (CM model) to estimate the age-specific first birth rate. The parameters of the CM model have conventional demographic meanings, and fit best with the aim of our study, which is to quantify the effects of remaining permanently childless and postponing fertility.

The CM model was developed to estimate the age at first marriage patterns of a birth cohort (Coale and Trussell 1978). The CM model has since been extended beyond its original purpose, and has often been applied to the first birth distribution by age (Bloom 1982a,b; Bloom and Trussell 1984; Henz and Huinink 1999; Rao 1987; Trussell and Bloom 1983). Previous studies successfully applied the CM model to various countries, including Canada, Columbia, Finland, Germany, Italy, and the US. The advantage of using the CM model is that its parameters have clear demographic meanings, which are as follows. The probability of first birth at age $x$ 
and time $t$, denoted as $f_{x, t}$, is expressed as:

$$
f_{x, t}=C_{t} \frac{1}{\sigma_{t}} a_{1} \exp \left[a_{2}\left(\frac{x-\mu_{t}}{\sigma_{t}}+a_{3}\right)-\exp \left\{-a_{4}\left(\frac{x-\mu_{t}}{\sigma_{t}}+a_{3}\right)\right\}\right],
$$

where $C_{t}$ pertains to the proportion of the cohort eventually having a child by age 50 at time $t, \mu_{t}$ refers to the mean age at first birth at time $t, \sigma_{t}$ is a measure of the standard deviation of age at first birth at time $t$, and the usual values for the constants are $a_{1}=1.281, a_{2}=-1.145, a_{3}=0.805$, and $a_{4}=1.896$. This equation is known as a standardised version of the CM model developed by Rodríguez and Trussell (1980).

Although several models have been used to estimate first birth patterns, these models are not fully applicable to our study. First, for one feature of the CM model (the convolution structure), an additional term has been proposed: namely, an exponentially distributed waiting time segment to account for the time from first marriage to first birth. However, Trussell and Bloom (1983) reported that the original CM model fitted better than the model with the waiting term. Thus, previous research applied the CM model to first birth patterns without using the additional waiting time segment (Bloom 1982a,b; Bloom and Trussell 1984, Henz and Huinink 1999, Rao 1987, Trussell and Bloom 1983). In addition, this approach is not theoretically appropriate given the current data. As nonmarital childbirth has become common in many high-income countries (Eurostat 2018; Department of Health and Human Services 2018), the first birth does not always occur after marriage. Thus, the additional term that considers the period from marriage to childbirth is not relevant to the data in our study. The second model is a log-logistic function (LL model). Henz and Huinink (1999) applied it to the first birth in the German data. However, it does not have a scale parameter, which indicates the proportion of the population who never had children. Hence, it is not applicable given our aim and decomposition method.

Although the CM model is widely used to study first birth trends, whether the $\mathrm{CM}$ model fits well with the observed pattern of the age at first birth has not been statistically examined. The goodness-of-fit using the Kolmogorov-Smirnov tests shows that the CM model estimates well the data for all the countries and years (see Appendix A). For these reasons, we have chosen to use the CM model to explore the changes over time in first birth behaviours and the expected years without children (EYWC).

However, the limitations of the CM model should be mentioned. There are statistical issues when the CM model is used to estimate the mean and the standard deviation of age at first birth (Bloom and Trussell 1984): (1) if the sample available for estimation is restricted to women who have become mothers on or before the survey date, a truncation bias problem will arise; and (2) if the data used for estimation refer to a sample of all women, there will be a censoring problem if any of the women who will ultimately have a first birth have not done so by the time of the survey (Bloom and Trussell 1984). We avoid those problems by using completed cohort fertility data from the HFD. 


\subsection{Expected years without children (EYWC)}

We use life expectancy to measure fertility behaviours. In classical life table methods, life expectancy between two ages (e.g., 0 and $X$ ) represents the area below a survival function from age zero to the fixed age $X$. This is interpreted as the average number of years people live between these ages (Preston et al. 2001). In this research analysing first birth trends, life expectancy is interpreted as the expected years without children, with a first birth representing a "death". The minimum age is the age of first menstruation and the maximum age is the age of menopause. Therefore, the EYWC from age 15 to age 50, denoted as ${ }_{35} e_{15}$, is calculated as ${ }_{35} e_{15}(t)=\int_{15}^{50} l_{x, t} d x$. It corresponds to the two shaded areas in Figure 1 for the

\section{Figure 1:}

Probability of remaining childless by age among a Canadian female birth cohort in 1940 and 1962

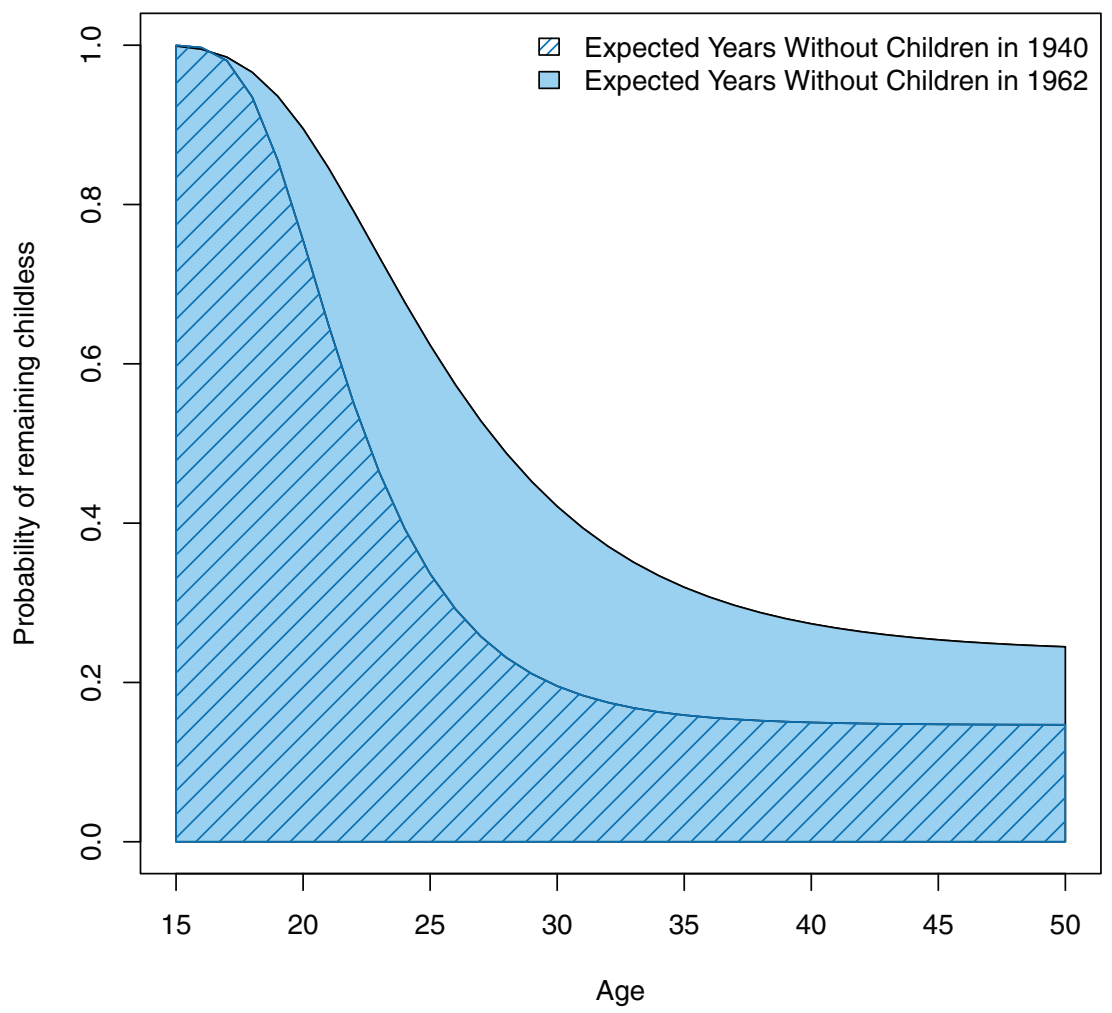

Note: The parameters of the probabilities of remaining childless are $C=0.85, \mu=23.10$, and $\sigma=4.14$ for the 1940 birth cohort and $C=0.76, \mu=26.98$, and $\sigma=6.88$ for the 1962 birth cohort.

Source: Authors' calculations using the Human Fertility Database. 
1940 and the 1962 birth cohorts. The use of EYWC has two primary advantages. First, as this index is able to capture fertility trends in one simple value, it can be used to numerically compare fertility trends at different times and in different countries. Second, it can take into account both the population having children and the population without children. While the most common indices used to study first birth trends are the mean age at first birth and the proportion of childless women, the EYWC index can reflect those two indices simultaneously. These features are very useful in the current context, in which both indices have an increasing trend.

\subsection{Decomposition method}

We applied the decomposition method developed by Mogi and Canudas-Romo (2018). A detailed explanation can be found in their study (Mogi and CanudasRomo 2018). The changes in EYWC over time, denoted as ${ }_{35} \dot{e}_{15}(t)$, are decomposed into three parameters: scale (the proportion of the cohort eventually having a child), location (the mean age at first birth), and variance (the standard deviation of age at first birth). The decomposition of ${ }_{35} \dot{e}_{15}(t)$ can be formulated as

$$
{ }_{35} \dot{e}_{15}(t)=\frac{\partial_{35} e_{15}(t)}{\partial C_{t}} \dot{C}_{t}+\frac{\partial_{35} e_{15}(t)}{\partial \mu_{t}} \dot{\mu}_{t}+\frac{\partial_{35} e_{15}(t)}{\partial \sigma_{t}} \dot{\sigma}_{t},
$$

where each term is the change in ${ }_{35} \dot{e}_{15}(t)$ resulting from changes in the scale, location, and variance. A dot on top of a variable indicates the derivative with respect to time. The largest value among these three components shows that the changes in EYWC are mainly caused by that factor; i.e., scale factor $\left(\frac{\partial_{35} e_{15}(t)}{\partial C_{t}} \dot{C}_{t}\right)$ : remaining permanently childless, location $\left(\frac{\partial_{35} e_{15}(t)}{\partial \mu_{t}} \dot{\mu}_{t}\right)$ : postponing first birth, or variance $\left(\frac{\partial_{35} e_{15}(t)}{\partial \sigma_{t}} \dot{\sigma}_{t}\right)$ : expansion effect. Appendix C explains the detailed method for estimating the three parameters of the CM model and applying the decomposition equation to discrete data.

\section{Results}

\subsection{Cross-country trend analysis of EYWC}

The trends in EYWC for the selected countries are presented in Figure 2.

Figure 2 shows that most of the countries in the study had an increasing trend in EYWC starting with the 1940s birth cohorts. The EYWC in Canada declined until the 1940s birth cohorts, and then started steeply increasing. The 1940 birth cohort in Canada had 12 years of EYWC. This value had increased to 16.6 years for the 1960 cohort. As EYWC represents the expected number of years without children starting from age 15, each number signifies that the expected age at first birth in the specific cohort in a country is $15+$ EYWC. Thus, we can interpret these 


\section{Figure 2:}

Time trends in expected years without children in eight countries

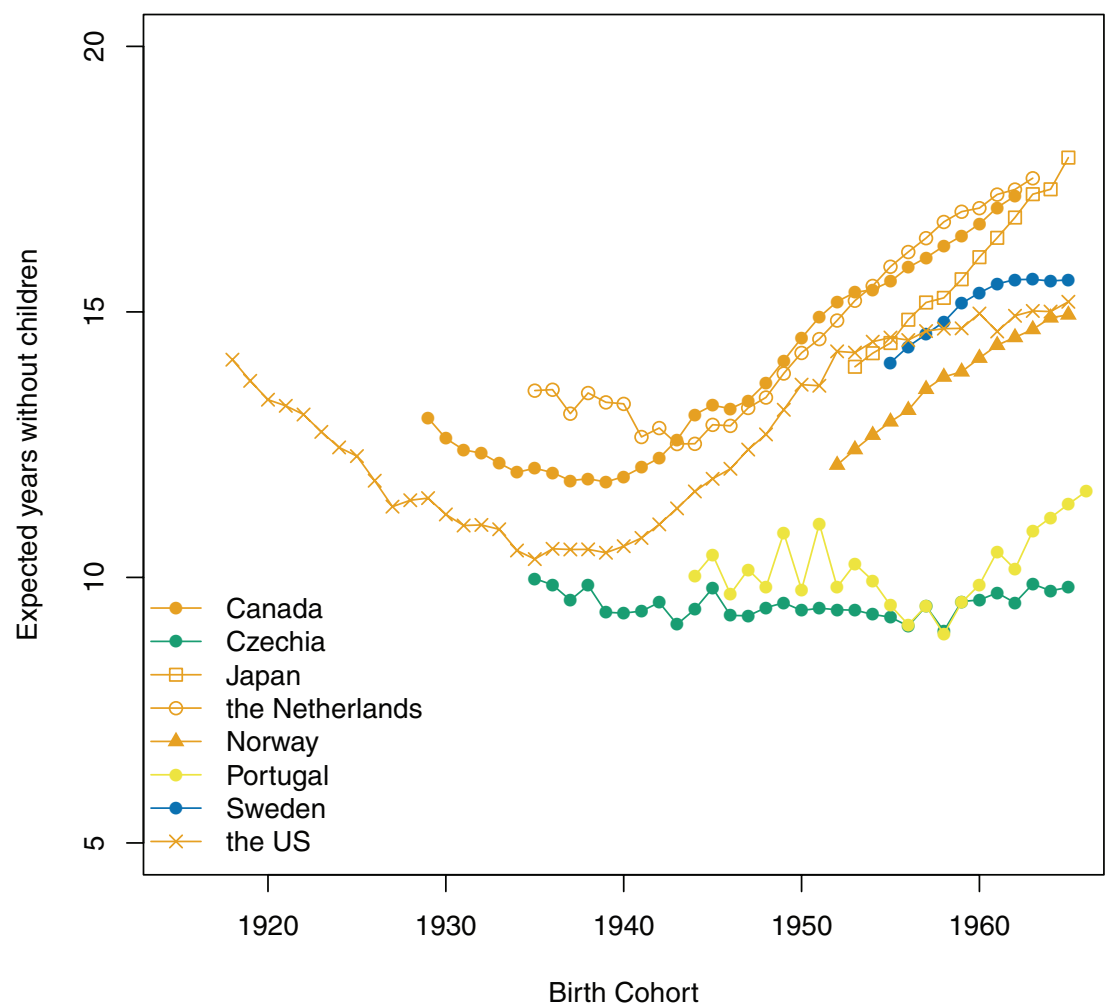

Source: Authors' calculations using the Human Fertility Database.

findings as showing that the expected age at first birth increased from $27(15+12)$ in the 1940 birth cohort to $31.6(15+16.6)$ in the 1960 birth cohort. The US had an increasing trend similar to that of Canada until the 1950s birth cohorts. In the US, the EYWC increased sharply from the 1940 birth cohort (10.5 years) to the 1950 birth cohort (13.6 years). However, this increasing trend slowed after the 1950 birth cohort. The EYWC in the US increased by only 1.3 years from the 1950 to the 1960 birth cohort. In the Netherlands, the EYWC increased starting with the 1945 birth cohort, from 13 years for the 1945 birth cohort to 17 years for the 1960 birth cohort. Moreover, in several other countries, such as in Japan and Norway, the EYWC displayed an increasing trend for all the observable periods. In Japan, the EYWC rose from 14 years for the 1953 birth cohort to 18 years for the 1965 birth cohort. In Norway, the EYWC increased from 12 years for the 1952 cohort to 15 years for the 1965 cohort.

The EYWC trends in Portugal, Sweden, and the Czech Republic differ from those in the countries discussed above. In Portugal, the EYWC fluctuated by 
approximately 10 years between the 1940s and 1950s birth cohorts. However, by the 1960 birth cohort, the EYWC in Portugal had increased, and it is currently estimated at 11.6 years for the latest observed birth cohort. By contrast, in the Czech Republic, the EYWC trend has been neither increasing nor decreasing, as it has plateaued at 10 years for all observable birth cohorts from 1935 to 1965 . Interestingly, in Sweden, the EYWC trend has also plateaued in recent cohorts. After increasing starting with the 1955 birth cohort (14.4 years), the EYWC trend had plateaued at 16 years by the 1960 birth cohort.

Among the latest birth cohorts we can observe, the EYWC was approximately 17.5 years in Canada, Japan, and the Netherlands; and was approximately 15 years in Norway, Sweden, and the US. The EYWC values in these countries were followed by those in Portugal, at 11.5 years; and in the Czech Republic, at less than 10 years. Lower EYWC values indicate that, on average, the women in the population gave birth to their first child at an early age. The latest cohort observed in Canada, Japan, and the Netherlands spent half of their reproductive period with no children (the expected age at first birth is $15+17.5=32.5$ ). In other words, these women have only have 17.5 years left in their reproductive period, on average, to have any subsequent children.

The main objective of this study is to investigate whether the changes in EYWC, as shown in Figure 2, are attributable to women remaining permanently childless or postponing childbirth, or to the expansion effect. We decompose EYWC from 1940 onwards; the results are presented in Figure 3.

\subsection{Decomposition of EYWC}

In Canada, the US, the Netherlands, Sweden, and Norway, the location parameter (the timing of first birth) was the most influential factor in the changes in EYWC after 1950. Table 1 shows that $74 \%$ of the increase in the EYWC in Canada from 1955 to 1960 was due to the increase in the average age at first birth. Similar results can be reported for the US: 68\% of the increase in the EYWC from 1958 to 1963 in the US can be attributed to the increase in the average age at first birth. Likewise, in Norway, the increase in the average age at first birth was responsible for $81 \%$ of the increase in the EYWC from 1957 to 1962. The results for the Netherlands and Sweden were very similar. These findings suggest that larger shares of the current birth cohorts in these countries have postponed childbirth rather than remaining permanently childless. The changes in the scale parameter and the proportion of women having children influenced the current increase in the EYWC of these countries to a lesser extent.

In addition, in the Netherlands (1955-1960) and Sweden (1960-1965), the value for the scale parameter in the most recent birth cohort was negative, which implies that the proportions of women having a first child increased in those periods. The negative value of the scale factor in Sweden is consistent with the current decrease in the proportion of childless women (Persson 2010; Miettinen et al. 2015). The higher 
Figure 3:

Decomposition of the change over time in females' expected years without children in eight countries

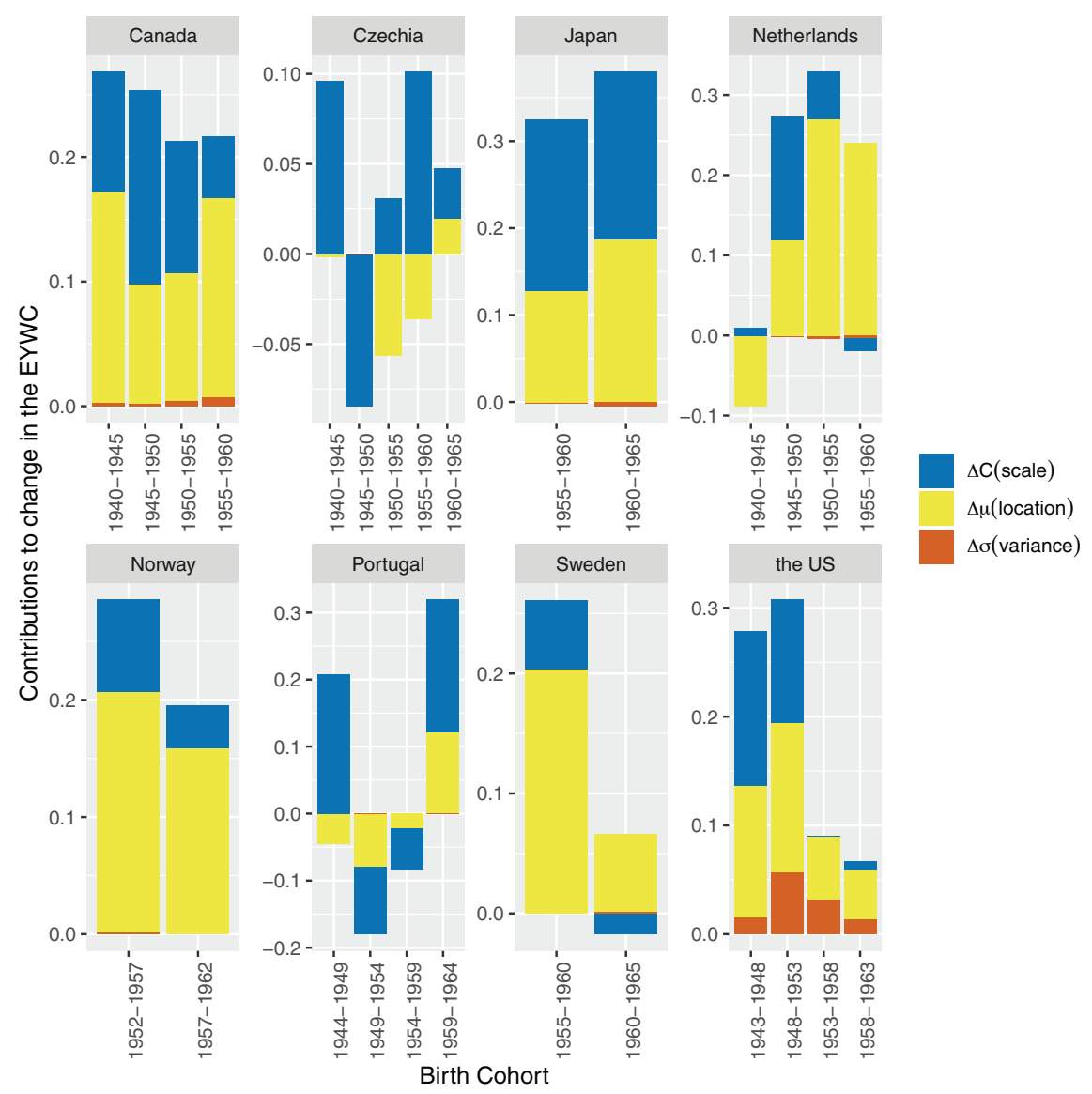

Note: scale: the proportion of the cohort eventually having a child; location: the mean age at first birth; and variance: the standard deviation of age at first birth.

Source: Authors' calculations using the Human Fertility Database.

educational category has a more distinct decreasing trend (Persson 2010). Therefore, this negative value could be mainly driven by women in a higher educational group.

However, the trends in Japan and Portugal differ from those in the other countries. The scale parameter, which indicates the proportion of women who eventually have a child, is the most influential factor in the changes in the EYWC in these countries after 1955 and 1959, respectively. For instance, Table 1 shows that $62 \%$ of the change in the EYWC in Portugal from 1959 to 1964 can be attributed to the scale parameter, which means that the shift was mainly attributable to women remaining 
permanently childless. Likewise, in Japan, the increase in EYWC was mainly due to the changes in the scale parameter, even though the location parameter had only approximately half as much impact on the latest change. This result indicates that in these countries, more women remained permanently childless than postponed

Table 1:

The contribution of three parameters (scale: the proportion of the cohort eventually having a child, location: the mean age at first birth, and variance: the standard deviation of age at first birth) to the changes in females' expected years without children over time $\left({ }_{35} \dot{e}_{15}(t)\right)$ in eight selected countries

\begin{tabular}{|c|c|c|c|c|c|c|}
\hline Country & $\begin{array}{l}\text { Birth } \\
\text { cohort }\end{array}$ & ${ }_{35} \dot{e}_{15}(t)$ & Scale & Location & Variance & $\begin{array}{c}\text { Sum of } \\
\text { all } \\
\text { components }\end{array}$ \\
\hline \multirow[t]{4}{*}{ Canada } & 1940-1945 & 0.2685 & $\begin{array}{c}0.0957 \\
(35.66)\end{array}$ & $\begin{array}{c}0.1698 \\
(63.26)\end{array}$ & $\begin{array}{l}0.0029 \\
(1.08)\end{array}$ & 0.2684 \\
\hline & $1945-1950$ & 0.2535 & $\begin{array}{c}0.1558 \\
(61.46)\end{array}$ & $\begin{array}{c}0.0951 \\
(37.51)\end{array}$ & $\begin{array}{l}0.0026 \\
(1.03)\end{array}$ & 0.2535 \\
\hline & 1950-1955 & 0.2129 & $\begin{array}{c}0.1059 \\
(49.74)\end{array}$ & $\begin{array}{c}0.1027 \\
(48.24)\end{array}$ & $\begin{array}{l}0.0043 \\
(2.02)\end{array}$ & 0.2129 \\
\hline & 1955-1960 & 0.2164 & $\begin{array}{c}0.0497 \\
(22.97)\end{array}$ & $\begin{array}{r}0.1597 \\
(73.80)\end{array}$ & $\begin{array}{l}0.0070 \\
(3.23)\end{array}$ & 0.2164 \\
\hline Czech & 1940-1945 & 0.0943 & 0.0963 & -0.0020 & 0.0000 & 0.0943 \\
\hline \multirow[t]{4}{*}{ Republic } & $1945-1950$ & -0.0845 & -0.0844 & -0.0001 & 0.0000 & 0.0845 \\
\hline & $1950-1955$ & -0.0253 & 0.0311 & -0.0565 & 0.0000 & -0.0254 \\
\hline & $1955-1960$ & 0.0651 & 0.1012 & -0.0361 & 0.0000 & 0.0651 \\
\hline & 1960-1965 & 0.0473 & $\begin{array}{c}0.0278 \\
(58.77)\end{array}$ & $\begin{array}{c}0.0195 \\
(41.23)\end{array}$ & $\begin{array}{l}0.0000 \\
(0.00)\end{array}$ & 0.0473 \\
\hline \multirow[t]{2}{*}{ Japan } & $1955-1960$ & 0.3232 & 0.1968 & 0.1276 & -0.0011 & 0.3232 \\
\hline & 1960-1965 & 0.3749 & 0.1923 & 0.1875 & -0.0048 & 0.3750 \\
\hline \multirow[t]{4}{*}{ Netherlands } & 1940-1945 & -0.0789 & 0.0094 & -0.0883 & 0.0000 & -0.0789 \\
\hline & $1945-1950$ & 0.2709 & 0.1536 & 0.1186 & -0.0013 & 0.2709 \\
\hline & 1950-1955 & 0.3247 & 0.0594 & 0.2695 & -0.0041 & 0.3249 \\
\hline & $1955-1960$ & 0.2205 & -0.0158 & 0.2395 & -0.0031 & 0.2206 \\
\hline \multirow[t]{2}{*}{ Norway } & 1952-1957 & 0.2856 & $\begin{array}{c}0.0790 \\
(27.66)\end{array}$ & $\begin{array}{c}0.2045 \\
(71.60)\end{array}$ & $\begin{array}{l}0.0021 \\
(0.74)\end{array}$ & 0.2856 \\
\hline & 1957-1962 & 0.1951 & $\begin{array}{c}0.0368 \\
(18.85)\end{array}$ & $\begin{array}{c}0.1582 \\
(81.05)\end{array}$ & $\begin{array}{l}0.0002 \\
(0.10)\end{array}$ & 0.1952 \\
\hline \multirow[t]{4}{*}{ Portugal } & 1944-1949 & 0.1611 & 0.2075 & -0.0462 & 0.0003 & 0.1615 \\
\hline & 1949-1954 & -0.1796 & -0.0996 & -0.0803 & 0.0003 & -0.1796 \\
\hline & 1954-1959 & -0.0823 & -0.0606 & -0.0216 & 0.0001 & -0.0824 \\
\hline & 1959-1964 & 0.3192 & $\begin{array}{c}0.1980 \\
(62.03)\end{array}$ & $\begin{array}{c}0.1205 \\
(37.75)\end{array}$ & $\begin{array}{l}0.0007 \\
(0.22)\end{array}$ & 0.3192 \\
\hline \multirow[t]{2}{*}{ Sweden } & 1955-1960 & 0.2611 & 0.0578 & 0.2037 & -0.0002 & 0.2613 \\
\hline & 1960-1965 & 0.0485 & -0.0173 & 0.0643 & 0.0015 & 0.0485 \\
\hline
\end{tabular}

Continued 
Table 1:

\section{Continued}

\begin{tabular}{lcccccc}
\hline Country & $\begin{array}{c}\text { Birth } \\
\text { cohort }\end{array}$ & ${ }_{35} \dot{\boldsymbol{e}}_{\mathbf{1 5}}(\boldsymbol{t})$ & Scale & Location & Variance & $\begin{array}{c}\text { Sum of } \\
\text { all } \\
\text { components }\end{array}$ \\
\hline US & $1943-1948$ & 0.2785 & 0.1422 & 0.1202 & 0.0160 & 0.2784 \\
& & & $(51.08)$ & $(43.18)$ & $(5.75)$ & \\
& $1948-1953$ & 0.3082 & 0.1131 & 0.1376 & 0.0568 & 0.3075 \\
& & & $(36.78)$ & $(44.75)$ & $(18.47)$ & \\
& \multirow{2}{*}{$1953-1958$} & 0.0902 & 0.0007 & 0.0578 & 0.0318 & 0.0902 \\
& & & $(0.78)$ & $(64.08)$ & $(35.25)$ & \\
& \multirow{2}{*}{$1958-1963$} & 0.0667 & 0.0077 & 0.0455 & 0.0136 & 0.0667 \\
& & & $(11.54)$ & $(68.22)$ & $(20.39)$ & \\
\hline
\end{tabular}

Note: Percentages are presented under each value in parentheses and are calculated only when all terms go in the same direction. The sum of all components (scale, location, and variance) varies slightly from the difference in the expected years without children $\left.{ }_{35} \dot{e}_{15}(t)\right)$ due to rounding the numbers to the third decimal point in the table.

Source: Authors' calculations using the Human Fertility Database.

their first birth to a later age. For Japan, the strong linkage between marriage and childbearing may be the key to understanding the large impact of the scale factor. As the nonmarital birth rate in Japan is still at a low level - i.e., 2.29\% in 2015 (National Institute of Population and Social Security Research 2017) - most births in that country occur in marital unions. Hence, the large influence of the scale factor in Japan may indicate that the never-married population in Japan is increasing. Indeed, between 1980 and 2015, the never-married population at age 50 increased from $2.6 \%$ to $23.4 \%$ for males and from $4.5 \%$ to $14.1 \%$ for females (National Institute of Population and Social Security Research 2017). In Japan, the shares of nevermarried people are almost equal to the shares of childless people. This explains why the scale factor plays a larger role in Japan than in the other countries. Interpreting the findings for the Czech Republic is difficult because its EYWC trend fluctuated.

The changes in the variance parameter were not found to be influential in the changes in the EYWC in any of the countries in our sample except the US. The much larger variance effect observed in the US may be attributable to the strong differentials in first birth behaviours by indicators of socio-economic status, such as educational level, union status, and race/ethnicity. Rendall et al. (2010) found that in the US, there has been a persistent trend of early first births among low-educated women, and a shift towards later first births among women with higher educational levels. Moreover, Chandola et al. (2002) suggested that this heterogeneity is related to marital status, with an early bulge linked to extra-marital births, often among solo mothers. They also argued that ethnic differences play an important role in explaining the variance in the first birth trends in the US. Likewise, Kostaki and Paraskevi (2007) linked the observed heterogeneity in first birth patterns in the US 
to a range of fertility determinants, including the rise of migrant populations in conjunction with racial and ethnic differences.

Overall, the results strongly indicate that changes in EYWC are mainly due to two factors: remaining permanently childless and postponing childbirth. Except in the US, the variability in the timing of childbirth is generally not found to be a factor in the changes in EYWC.

\section{Conclusion}

Increases in the proportion of childless women, the mean age at first birth, and the variance in the timing of the first birth have been observed in high-income countries (Kohler and Philipov 2001; Kreyenfeld and Konietzka 2017; Mills et al. 2011). These increases have led researchers to ask an important question: Which of three effects - remaining permanently childless, postponing the first birth, or the expansion of the standard deviation of the mean age at first birth - has the most impact on the changes in the first birth trend?

We used cohort data for eight high-income countries from the Human Fertility Database (HFD) and applied the decomposition method developed by Mogi and Canudas-Romo (2018) to quantify the effect of the aforementioned components on the changes in Expected Years Without Children (EYWC) over time. Our analysis of the trends showed that the EYWC in Canada, the US, the Netherlands, Japan, and Norway increased steadily across cohorts. In Sweden, EYWC increased until the 1960 birth cohort, and then remained at the same level. In Portugal, the EYWC increased starting with the late 1950s cohorts after fluctuating. In the Czech Republic, no clear EYWC trends across cohorts could be observed. The decomposition results strongly indicate that changes in EYWC are mainly due to two factors: remaining permanently childless and the postponement of childbirth. The findings of the decomposition analysis show that in Canada, the US, the Netherlands, Sweden, and Norway, more people postpone the first birth to a higher age than remain permanently childless. In these countries, the EYWC has an increasing trend mainly because their female populations have delayed childbirth. This could be the result of improvements in female education and labour force participation and better access to effective contraceptive methods. By contrast, in Japan and Portugal, more women remain permanently childless than postpone childbirth. The strong link between marriage and childbirth in Japan may be an important key to understanding the large impact of the scale factor in that country (National Institute of Population and Social Security Research 2017). For all periods and for all of the countries analysed except the US, the variance factor did not have a large impact on the changes in EYWC. This might be due to the greater heterogeneity in the first birth trend by socio-economic status in the US compared to in other countries (Chandola et al. 2002; Kostaki and Paraskevi 2007; Rendall et al. 2010).

Finally, in future research, this decomposition method could be applied to subpopulations, such as educational groups. It is well known that the timing of first 
birth and the share of childless women differ significantly by education (Beaujouan et al. 2016; Kneale and Joshi 2008). Applying this method to union status (e.g., single, cohabitation, married) and race/ethnicity would also be beneficial.

\section{Acknowledgements}

The first author is part of the project that has received funding from Spanish Ministry of Science, Innovation and Universities, National R\&D\&I Plan GLOBFAM (RTI2018-096730-B-I00).

\section{References}

Albertini, M. and M. Kohli 2009. What childless older people give: Is the generational link broken? Ageing and Society 29(08): 1261-1274. https://doi.org/10.1017/ S0144686X0999033X.

Andersson, G., E. Thomson and A. Duntava 2017. Life-table representations of family dynamics in the 21st century. Demographic Research 37(35): 1081-1230. https://doi.org/ 10.4054/DemRes.2017.37.35.

Beaujouan, E., Z. Brzozowska and K. Zeman 2016. The limited effect of increasing educational attainment on childlessness trends in twentieth-century Europe, women born 1916-65. Population Studies 70(3): 275-291. https://doi.org/10.1080/00324728.2016. 1206210.

Bergeron-Boucher, M.-P., M. Ebeling and V. Canudas-Romo 2015. Decomposing changes in life expectancy: Compression versus shifting mortality. Demographic Research 33(14): 391-424. https://doi.org/10.4054/DemRes.2015.33.14.

Bloom, D. E. 1982a. Age patterns of women at first birth. Genus 38(3-4): 101-128. https://doi.org/10.2307/2061348.

Bloom, D. E. 1982b. What's happening to the age at first birth in the United States? A study of recent cohorts. Demography 19(3): 351-370. https://doi.org/10.2307/2060976.

Bloom, D. E. and J. Trussell 1984. What are the determinants of delayed childbearing and permanent childlessness in the United States? Demography 21(4): 591-611. https://doi.org/10.2307/2060917.

Bongaarts, J. and G. Feeney 2006. The quantum and tempo of life-cycle events. Vienna Yearbook of Population Research 4: 115-151. https://doi.org/10.1553/ populationyearbook2006s 115 .

Budig, M. J., J. Misra and I. Boeckmann 2012. The motherhood penalty in cross-national perspective: The importance of workfamily policies and cultural attitudes. Social Politics: International Studies in Gender, State E Society 19(2): 163-193. https://doi.org/10.1093/ $\mathrm{sp} / \mathrm{j} x \mathrm{~s} 006$.

Chandola, T., D. A. Coleman and R. W. Hiorns 2002. Distinctive features of age-specific fertility profiles in the English-speaking world: Common patterns in Australia, Canada, 
New Zealand and the United States, 1970-98. Population Studies 56(2): 181-200. https://doi.org/10.1080/00324720215929.

Coale, A. J. and T. J. Trussell 1978. Technical note: Finding the two parameters that specify a model schedule of marital fertility. Population Index 44(2): 203-213.

Department of Health and Human Services 2018. National Center for Health Statistics. [electric resource]. https://catalog.data.gov/dataset/nonmarital-birth-rates-by-age-groupfor-all-women-age-15-44-united-states-1980-2013 (accessed on 23 November 2018).

Elzinga, C. H. and A. C. Liefbroer 2007. De-standardization of family-life trajectories of young adults: A cross-national comparison using sequence analysis. European Journal of Population/Revue Européenne de Démographie 23(3): 225-250. https://doi.org/10.1007/ s10680-007-9133-7.

Eurostat 2018. Eurostat Database [electric resource]. https://ec.europa.eu/eurostat/web/ population-demography-migration-projections/births-fertility-data/main-tables (accessed on 23 November 2018).

Frejka, T. 2017. Childlessness in the United States. In: Childlessness in Europe: Contexts, causes, and consequences, eds. M. Kreyenfeld and D. Konietzka, 159-179. Cham: Springer International Publishing.

Henz, U. and J. Huinink, 1999. Problems concerning the parametric analysis of the age at first birth. Mathematical Population Studies 7(2): 131-145. https://doi.org/10.1080/ 08898489909525451.

Huijts, T., G. Kraaykamp and S. V. Subramanian 2013. Childlessness and psychological wellbeing in context: A multilevel study on 24 European countries. European Sociological Review 29(1): 32-47. https://doi.org/10.1093/esr/jcr037.

Human Fertility Database 2018. Max Planck Institute for Demographic Research (Germany) and Vienna Institute of Demography (Austria). www.humanfertility.org (data downloaded on 1 August 2018).

Kendig, H., P. A. Dykstra, R. I. van Gaalen and T. Melkas, 2007. Health of aging parents and childless individuals. Journal of Family Issues 28(11): 1457-1486. https://doi.org/10. 1177/0192513X07303896.

Kneale, D. and H. Joshi 2008. Postponement and childlessness: Evidence from two British cohorts. Demographic Research 19(58): 1935-1968. https://doi.org/10.4054/DemRes. 2008.19.58.

Kohler, H.-P. and D. Philipov, 2001. Variance effects in the Bongaarts-Feeney formula. Demography 38(1): 1-16. https://doi.org/10.1353/dem.2001.0004.

Kostaki, A. and P. Paraskevi 2007. Modeling fertility in modern populations. Demographic Research 16(6): 141-194. https://doi.org/10.4054/DemRes.2007.16.6.

Kreyenfeld, M. and D. Konietzka 2017. Childlessness in Europe: Contexts, causes, and consequences. Demographic Research Monographs. Cham: Springer International Publishing.

Miettinen, A., A. Rotkirch, I. Szalma, A. Donno and M.-L. Tanturri 2015. Increasing childlessness in Europe: Time trends and country differences. Families And Societies Working Paper Series 33: 1-66. 
Mills, M., R. R. Rindfuss, P. McDonald, E. te Velde and ESHRE reproduction and society task force 2011. Why do people postpone parenthood? Reasons and social policy incentives. Human Reproduction Update 17(6): 848-860.

Mogi, R. and V. Canudas-Romo 2018. Expected years ever married. Demographic Research 38(47): 1423-1456. https://doi.org/10.4054/DemRes.2018.38.47.

National Institute of Population and Social Security Research 2017. Recent demographic statistics. Tokyo [in Japanese]. National Institute of Population and Social Security Research.

Persson, L. 2010. Trend reversal in childlessness in Sweden. In: Work session on demographic projections, 129-135. Methodologies and working papers. Luxembourg: Publications Office of the European Union.

Preston, S., P. Heuveline and M. Guillot 2001. Demography: Measuring and modeling population processes. Oxford: Blackwell.

Rao, K. V. 1987. Demographic models of age at first marriage and first birth: An application to Canadian data. Digitized theses.

Ravanera, Z. and R. Beaujot 2014. Childlessness of men in Canada: Result of a waiting game in a changing family context. Canadian Studies in Population 41(1-2): 38-60. https://doi.org/10.25336/P6J02Q.

Raymo, J. M., H. Park, Y. Xie and W.-J. J. Yeung 2015. Marriage and family in East Asia: Continuity and change. Annual Review of Sociology 41(1): 471-492. https://doi.org/10. 1146/annurev-soc-073014-112428.

Rendall, M., E. Aracil, C. Bagavos, C. Couet, A. DeRose, P. DiGiulio, T. Lappegard, I. RobertBobée, M. Rønsen, S. Smallwood and G. Verropoulou 2010. Increasingly heterogeneous ages at first birth by education in Southern European and Anglo-American family-policy regimes: A seven-country comparison by birth cohort. Population Studies 64(3): 209-227. https://doi.org/10.1080/00324728.2010.512392.

Rodríguez, G. and J. Trussell 1980. Maximum likelihood estimation of the parameters of Coale's model nuptiality schedule from survey data. Voorburg: International Statistical Institute (World Fertility Survey Technical Bulletins, 7).

Sobotka, T. 2017. Childlessness in Europe: Reconstructing long-term trends among women born in 1900-1972. In Childlessness in Europe: Contexts, causes, and consequences, eds. M. Kreyenfeld and D. Konietzka, 17-53. Cham: Springer International Publishing.

te Velde, E., D. Habbema, H. Leridon and M. Eijkemans 2012. The effect of postponement of first motherhood on permanent involuntary childlessness and total fertility rate in six European countries since the 1970s. Human Reproduction 27(4): 1179-1183. https://doi.org/10.1093/humrep/der455.

Trussell, J. and D. E. Bloom 1983. Estimating the co-variates of age at marriage and first birth. Population Studies 37(3): 403-416.

Vaupel, J. W. and V. Canudas-Romo 2003. Decomposing change in life expectancy: A bouquet of formulas in honor of Nathan Keyfitz's 90th birthday. Demography 40(2): 201-216. https://doi.org/10.1353/dem.2003.0018.

Zhang, Z. and M. D. Hayward, 2001. Childlessness and the psychological well-being of older persons. The Journals of Gerontology Series B: Psychological Sciences and Social Sciences 56(5): S311-S320. https://doi.org/10.1093/geronb/56.5.S311. 


\section{Appendix A: The statistical test of the CM model}

We conducted a statistical examination of the CM model using the KolmogorovSmirnov test (KS test). The KS test is a nonparametric test to check the goodnessof-fit of the observed distribution and the estimated one by the CM model. The test statistic D of the KS test quantifies the supremum distance between the empirical distribution function of the data and the cumulative distribution function of the CM distribution. The null distribution of this statistic is calculated under the null hypothesis that the data follow the CM distribution. Thus, a p-value greater than $\alpha=0.05$ indicates that the data and the CM model have a good fit. As Table A.1 shows, the CM model estimated the observed data statistically well for all countries and birth cohorts.

Table A.1:

Goodness-of-fit of the CM model using the Kolmogorov-Smirnov test

\begin{tabular}{lccclccc}
\hline Country & $\begin{array}{c}\text { Birth } \\
\text { cohort }\end{array}$ & D & P-value & Country & $\begin{array}{c}\text { Birth } \\
\text { cohort }\end{array}$ & D & P-value \\
\hline Canada & 1940 & 0.1429 & 0.8745 & Norway & 1952 & 0.1429 & 0.8674 \\
& 1945 & 0.1714 & 0.6902 & & 1957 & 0.2000 & 0.4858 \\
& 1950 & 0.1714 & 0.6902 & & 1962 & 0.1714 & 0.6902 \\
& 1955 & 0.1714 & 0.6902 & Portugal & 1944 & 0.2000 & 0.4916 \\
Czech Republic & 1960 & 0.1714 & 0.6902 & & 1949 & 0.1429 & 0.8674 \\
& 1940 & 0.1143 & 0.9794 & & 1954 & 0.1143 & 0.9763 \\
& 1945 & 0.1429 & 0.8674 & & 1959 & 0.1143 & 0.9794 \\
& 1950 & 0.1143 & 0.9763 & & 1964 & 0.1714 & 0.6902 \\
Japan & 1955 & 0.0857 & 0.9995 & Sweden & 1955 & 0.1714 & 0.6902 \\
& 1960 & 0.1143 & 0.9763 & & 1960 & 0.1714 & 0.6902 \\
& 1965 & 0.1143 & 0.9763 & & 1965 & 0.1429 & 0.8745 \\
Netherlands & 1955 & 0.1143 & 0.9794 & US & 1943 & 0.1143 & 0.9794 \\
& 1960 & 0.1143 & 0.9794 & & 1948 & 0.1429 & 0.8745 \\
& 1965 & 0.1714 & 0.6902 & & 1953 & 0.1714 & 0.6902 \\
& 1940 & 0.1714 & 0.6826 & & 1958 & 0.1714 & 0.6902 \\
& 1945 & 0.1143 & 0.9763 & & 1963 & 0.1714 & 0.6902 \\
& 1950 & 0.1429 & 0.8745 & & & & \\
& 1955 & 0.2000 & 0.4916 & & & & \\
\hline
\end{tabular}

Source: Authors' calculations using the Human Fertility Database. 


\section{Appendix B: Calculation process: Expected years without children}

The life expectancy from age zero to age $X$ is shown as

$$
{ }_{x} e_{0}(t)=\int_{0}^{X} l_{x, t} d x .
$$

We call the life expectancy between age 15 and age 50 the expected years without children (denoted ${ }_{35} e_{15}(t)$ ). It is formulated as follows:

$$
\begin{aligned}
{ }_{35} e_{15}(t) & =\int_{15}^{50} l_{x, t} d x \\
& =35-\int_{15}^{50} F_{x, t} d x,
\end{aligned}
$$

where $l_{x}$ is the probability of remaining childless and $F_{x}$ is its cumulative probability function. The detailed calculation procedure can be found in Mogi and CanudasRomo (2018).

\section{Appendix C: The decomposition to discrete data}

Three parameters of $f_{x}$ are estimated using the maximum likelihood estimation method, as suggested by Rodríguez and Trussell (1980):

$$
\operatorname{lnLH}=\sum_{15}^{49}\left(\text { With }_{x} \log \left[F_{(x+0.5)}\right]+\text { Without }_{x} \log \left[1-F_{(x+0.5)}\right]\right),
$$

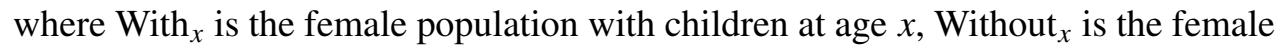
population without children at age $x$, and $F_{x}$ is the cumulative probability function at age $x$.

Vaupel and Canudas-Romo (2003) and Bergeron-Boucher et al. (2015) applied the continuous decomposition equation to discrete time data, and we followed their method. To estimate each function by applying our decomposition method to discrete time data, we use the midpoint over a time interval (Preston et al. 2001). As Mogi and Canudas-Romo (2018) assumed for the nuptiality decomposition, an exponential change assumption is used for the functions except EYWC, and the midpoint of EYWC is assumed to be a linear change in the interval. The details can be found in Mogi and Canudas-Romo (2018). 
Open Access This article is published under the terms of the Creative Commons Attribution 4.0 International License (https://creativecommons.org/licenses/by/4.0/) that allows the sharing, use and adaptation in any medium, provided that the user gives appropriate credit, provides a link to the license, and indicates if changes were made. 